\title{
ENERGY BALANCE AND SECOND LAW ANALYSIS APPLIED TO BUILDINGS: AN OPPORTUNITY FOR BEJAN'S THEORY
}

\author{
Cesare Biserni * and Massimo Garai \\ Department of Industrial Engineering, Viale Risorgimento 2, 40136 Bologna, Italy \\ Email: cesare.biserni@unibo.it
}

\begin{abstract}
Building energy assessment is usually performed based on fundamentals of the First Law of Thermodynamics, which is mainly concerned on quantitative energy aspects. However, this approach does not provide a faithful thermodynamic evaluation of the overall energy conversion processes that occur in buildings, and a more robust approach should be followed. This paper presents an exploratory work to study the relevance of Second Law analysis: in addition to the calculation of energy balances, the concept of exergy is used to evaluate the quality of energy sources, resulting in a higher flexibility of strategies to optimize a building design. In this context, a digression on the potentiality of constructal theory, that can be considered a law of thermodynamics, has been outlined.
\end{abstract}

Keywords: Energy analysis in buildings, Exergy and Second Law of Thermodynamics, Constructal law.

\section{INTRODUCTION}

The rapidly growing world energy consumption [1] has raised concerns over supply difficulties, depletion of energy resources and negative environmental impacts. Nonrenewable fuels currently supply about $87 \%$ of the global total primary energy [2], with fossil fuels accounting for $82 \%$, to which oil, coal and fossil gas contribute $32 \%, 29 \%$ and $21 \%$, respectively [3]. Within the European Union (EU), oil, coal and fossil gas provide about $37 \%, 16 \%$, and $25 \%$ of the total primary energy use, respectively [4]. The International Energy Agency global energy system scenarios for 20092035 anticipate that fossil fuels may increase in use and remain the dominant energy source [5]. Moreover, long-term energy mix scenarios by the Intergovernmental Panel on Climate Change suggest that fossil fuels are likely to contribute at significant levels in the year 2100 [6]. In the EU where buildings account for $41 \%$ of the total final energy use, efforts are ongoing to improve buildings energy efficiency and thereby reduce dependency on fossil fuels $[7,8]$. Therefore, predicting energy consumption starting from the early stages of building design is important for energy and emissions reduction efforts. Predicting building energy consumption [9] is a complicated task since it depends on multiple variables such as building characteristics, energy systems characteristics, control and maintenance, weather parameters and behaviour of occupants. Buildings have also long life spans and energy use and emissions occur over the various life cycle phases, from the extraction and production of the building materials, transportation, construction, operation, maintenance/renovation to the demolition of the buildings. Low-energy buildings [10] are mainly achieved by increased use of materials such as insulation and glazing with improved transmittance-values to achieve better thermal performance and improved air tightness. Both the improvement of energy-efficiency standards and the deployment of low-energy buildings typically focus on reducing the energy use for building operation.

Building energy assessment is usually performed based on fundamentals of the First Law of Thermodynamics, which is especially concerned on quantitative energy aspects [11]. However, this approach does not provide an exhaustive thermodynamic evaluation of the overall energy conversion processes that occur in buildings, and a more robust approach should be performed. The exergy analysis $[12,13]$ is a useful method that combines First Law and Second Law perspectives and has been applied in many related engineering fields, such us building energy systems. This paper presents an exploratory work to study the relevance of Second Law analysis: in addition to the calculation of energy balances, the concept of exergy is used to evaluate the quality of energy sources, resulting in a higher flexibility of strategies to optimize a building design.

\section{ENERGY ANALYSIS}

The building energy model is based on the building energy balances for a zone and for a surface. It is considered as a one-zone model and all the walls are adjacent to the outdoor environment. More details on the mathematical description of the building thermal energy model can be found in the TRNSYS user manual [14] and in Ref. [15]. The building energy balance for a zone is a non-geometrical balance model with one air node per zone, representing the thermal capacity of the zone air volume. In the non-geometrical balance model any air point in the zone has the same properties (e.g. 
temperature and humidity). The building energy balance for a zone is shown as Eq. (1), which refers to the TRNSYS output in the multi-zone building component "NTYPE 904":

$$
\frac{D Q_{\text {air }}}{d t}=\dot{Q}_{\text {heating }}-\dot{Q}_{\text {cooling }}+\dot{Q}_{\mathrm{inf}}+\dot{Q}_{\text {vent }}+\dot{Q}_{\text {tran }}+\dot{Q}_{\text {gain }}+\dot{Q}_{\text {sol }}
$$

$\mathrm{DQ}_{\text {air }} / \mathrm{dt}$ is the change of the thermal energy of the air in the zone in the time interval dt. $\dot{Q}_{\text {heating }}$ and $\dot{Q}_{\text {cooling }}$ are the thermal energy supplied by heating and cooling equipments per unit time, respectively. $\dot{Q}_{\text {inf }}$ and $\dot{Q}_{\text {vent }}$ are the thermal gains from infiltration and ventilation, respectively. $\dot{Q}_{\text {tran }}$ is the thermal gain by thermal transmission between the inner surface nodes and environment, via the walls, containing the total transmitted part and the thermally accumulated part in the wall. $\dot{Q}_{\text {gain }}$ is the (convective and radiant) internal thermal energy gain per unit time from occupants and appliances. $\dot{Q}_{s o l}$ is solar gains, including both direct and diffuse parts, absorbed on the boundary surfaces of the zone. The absorbed solar gains into the inside surfaces of all windows are also taken into account. The system boundary for this energy balance includes the inside surface nodes of all surfaces of a zone, and therefore the balance also includes all radiant energy flows. The system boundary does not include the inside of any wall, so the energy from an active layer and the stored energy in walls are not part of this balance, but of the detailed balance for surfaces, illustrated according to the TRNSYS output in the multi-zone building component "NTYPE 906":

$$
\frac{D Q_{\text {surface }}}{d t}=-\dot{Q}_{\text {com }, i}+\dot{Q}_{\text {com }, o}+\dot{Q}_{r, \text { surface }, i}+\dot{Q}_{r, \text { surface }, o}
$$

DQ $Q_{\text {surface }} / \mathrm{dt}$ is the change of the thermal energy accumulated in the surfaces in the time interval $\mathrm{dt}$. The thermal energy $\mathrm{Q}_{\text {surface }}$ represents heat accumulated in the walls. $\dot{Q}_{\text {com }, i}$ and $\dot{Q}_{\text {com,o }}$ are the combined (convective and radiant) thermal power flows into the zone, and from outside to the building envelope, respectively. $\dot{Q}_{r, \text { surface, } i}$ and $\dot{Q}_{r, \text { surface,o }}$ are the total radiant gains for the inside and outside nodes on building envelope surfaces, respectively. The summation of $\dot{Q}_{\text {com,i }}$ and $\dot{Q}_{r, \text { surface, } i}$ is equal to $\dot{Q}_{\text {tran }}$ in Eq. (1). Therefore, $\mathrm{DQ}_{\text {surface }}$ is the amount of energy that is absorbed in the surfaces in the time interval dt, and the summation of $\dot{Q}_{\text {com,o }}$ and $\dot{Q}_{r, \text { surface,o }}$ is the thermal energy per unit time released to the environment from the outer surfaces.

\section{EXERGY CALCULATIONS}

For the exergy calculation, one has to set up the exergy balance equation for each sub-system as described in the following. First, one has to set up the energy and entropy balance equations of each sub-system which, are for a steadystate case:

$$
\dot{Q}_{\text {in }}=\dot{Q}_{\text {out }}
$$

with $\dot{Q}_{i n}$ being the rate at which energy is supplied to a subsystem $\left[\mathrm{W} / \mathrm{m}^{2}\right]$ and $\dot{Q}_{\text {out }}$ the rate at which energy leaves it $\left[\mathrm{W} / \mathrm{m}^{2}\right]$; all terms are expressed per unit surface and unit time. Moreover

$$
\frac{\dot{Q}_{\text {in }}}{T_{\text {in }}}+\dot{S}_{g}=\frac{\dot{Q}_{\text {out }}}{T_{\text {out }}}
$$

with $\dot{S}_{g}$ being the rate of entropy generation $\left[\mathrm{W} / \mathrm{m}^{2} \mathrm{~K}\right], \mathrm{T}_{\text {in }}$ the temperature associated with the power supplied, $\dot{Q}_{i n}$, and $\mathrm{T}_{\text {out }}$ the temperature associated with the power left, $\dot{Q}_{\text {out }}$. Both temperatures have to be expressed in kelvin. Having set up these balances, the next step is to assume a common environmental temperature for all of the sub-systems, $\mathrm{T}_{0}$ also is expressed in kelvin. The exergy balance equation then turns out to be the difference between Eq.(3) and the product of Eq.(4) with the environmental temperature.

Namely,

$$
\dot{Q}_{\text {in }}\left(1-\frac{T_{0}}{T_{\text {in }}}\right)-\dot{S}_{g} T_{0}=\dot{Q}_{\text {out }}\left(1-\frac{T_{0}}{T_{\text {out }}}\right)
$$

Where the first part of Eq.(5) is the the rate of exergy entering the sub-system, the second part the rate of exergy consumed and the third part the rate of exergy leaving the subsystem.

In Ref. [16], Appendix A, the exergy balance is referred to four sub-systems, namely the building envelope, the room air, the heat pump and the power supply, together with the human occupant behavioural model. The coefficient of performance (COP) of the heat pump is needed in order to estimate the value of exergy consumed in the heat pump subsystem. Angelotti et.Al. [17] calculated the COP according to the TRNSYS Library, as a function of the outdoor air temperature:

$$
C O P=l_{1}+l_{2} \theta_{\text {out }}
$$

Where $l_{1}$ and $l_{2}$ are constants related to the chosen heat pump and $\theta_{\text {out }}$ is the outdoor air temperature in Celsius degrees. Eq. (6) is valid with reference to the case of heating the indoor air temperature to $20{ }^{\circ} \mathrm{C}$. However, if the occupant behaviour has to be contemplated, the chosen indoor air temperature values are not necessarily the constants reported in textbooks and manuals. Consequently, both indoor and outdoor air temperatures should affect the COP value for the heat pump of the AC-unit:

$$
C O P_{H}=k_{1}+k_{2}\left(\frac{1.4 T_{\text {room }}-101.7}{1.4 T_{\text {room }}-0.75 T_{\text {out }}-170.1}\right)
$$

Assuming $\mathrm{k}_{1}$ and $\mathrm{k}_{2}$ constant, further calculations on the occupants behaviour can be found in Ref. [16]. 


\section{DISCUSSION AND CONCLUDING REMARKS: A CHALLENGE FOR THE CONSTRUCTAL THEORY}

The energy conservation Law has been here outlined with reference to the building system. Therefore, the exergy balance has been performed as a complementary method to estimate quantity and quality aspects on energy utilization. The Constructal law was initially formulated by Bejan in 1996 [18] as a principle of generation of flow configuration: "For a finite-size flow system to persist in time (to live) it must evolve in such a way that it provides easier and easier access to the currents that flows through it". Ref. [19] illustrates why the constructal law is even a law of thermodynamics but it is at the same time distinct and/or complementary to the other principles of thermodynamics. The first law accounts for a quantitative energy balance while the second law significance is linked to the irreversibility or entropy generation that prevents us from extracting all possible energy as work from various sources. The concept of quality of energy sources and energy conversion is at the basis of the exergy calculations here performed in Paragraph 3. It is worth knowing that the First and Second Laws of Thermodynamics speak of systems (the building in the case here treated) intended as "black boxes". They do not say anything about the possible internal configurations: classical thermodynamics is not concerned with non-equilibrium flow systems. The time sequence of drawings towards optimal configurations is the phenomenon covered by the Constructal Law, which is now leading in many directions. In this context, the investigation aimed to enhance the building performance represents one of the most promising challenge for the Constructal theory.

\section{ACKNOWLEDGMENT}

The Authors wish to thank the Italian Ministry of Education, University and Research for funding this study.

\section{REFERENCES}

1. Dodoo, A., Gustavsson, L., Sathre, R., "Lifecycle primary energy analysis of low-energy timber building systems for multi-storey residential buildings," Energy and Buildings 81, 84-97, 2014. DOI: 10.1016/j.enbuild.2014.06.003.

2. IEA. (International Energy Agency), FAQs: Renewable energy, 2013.

3. IEA. (International Energy Agency), Key World Energy Statistics, 2013.

4. EEA. (European Environment Agency), Primary energy consumption by fuel in the EU-27, 2012.

5. IEA. (International Energy Agency), World Energy Outlook 2011, 2011.
6. IPCC (Intergovernmental Panel on Climate Change), Special Report on Emissions Scenarios, Cambridge University Press, Cambridge, UK, 2000.

7. Enerdata, Energy Efficiency Trends in Buildings in the EU, Lessons from the ODYSSEE MURE project, 2012.

8. European Commission Energy Efficiency Plan, COM (2011) 109 final, Brussels, Belgium, 2011.

9. Asadia, S., Amiria, S.S., Mottahedi, M., "On the development of multi-linear regression analysis to assess energy consumption in the early stages of building design," Energy and Buildings, 85, 246-255, 2014. DOI: 10.1016/j.enbuild.2014.07.096.

10. Tettey, U.Y.A., Dodoo, A., Gustavsson, L., "Effects of different insulation materials on primary energy and $\mathrm{CO}_{2}$ emission of a multi-storey residential building," Energy and Buildings 82, 369-377, 2014. DOI: 10.1016/j.enbuild.2014.07.009.

11. Goncalves, P., Gaspar, A.R., da Silva, M.G., "Comparative energy and exergy performance of heating options in buildings under different climatic conditions," Energy and Buildings, 61, 288-297, 2013. DOI 10.1016/j.enbuild.2013.02.023.

12. Yucer, C.T., Hepbasli, A., "Thermodynamic analysis of a building using exergy analysis method," Energy and Buildings 43, 536-542, 2011. DOI 10.1016/j.enbuild.2010.10.019.

13. El Shenawy, A., Zmeureanu, R., "Exergy-based index for assessing the building sustainability," Building and Environment, 60, 202-210, 2013. DOI: 10.1016/j.buildenv.2012.10.019.

14. Solar Energy Laboratory, Manual of TRNSYS $17.01-\mathrm{a}$ TRaNsient SYstem Simulation program, 2012.

15. Sakulpipatsin, P., Itard, L.C.M., Van der Kooi, H.J., Boelman, E.C., Luscuere, P.G., "An exergy application for analysis of buildings and HVAC systems," Energy and Buildings 42, 90-99, 2010. DOI: 10.1016/j.enbuild.2009.07.015.

16. Schweiker, M., Shukuya, M., "Comparative effects of building envelope improvements and occupant behavioural changes on the exergy consumption for heating and cooling," Energy Policy 38, 2976-2986, 2010. DOI: 10.1016/j.enpol.2010.01.035.

17. Angelotti, A., Caputo, P., "The exergy approach for the evaluation of heating and cooling technologies; first results comparing steady state and dynamic simulations," Proceedings of $2^{\text {nd }}$ PALENC Conference and $28^{\text {th }}$ AIVC Conference on Building Low Energy Cooling and Advanced Ventilation Technologies in the 21st Century, Heliotopos Conferences Ltd., pp.59-64, 2007.

18. Bejan, A., Shape and Structure: from Engineering to Nature, Cambridge University Press, UK, 2000.

19. Bejan, A., Lorente, S., Design with Constructal Theory, John Wiley and Sons Inc., US, 2008. DOI: $\underline{10.1002 / 9780470432709}$. 